\title{
Percepções de egressos do curso de Odontologia sobre o estágio supervisionado na Atenção Primária em Saúde
}

\author{
Mariana Dantas de Oliveira*; Maria Leal Lima Silva**; Tatiana Frederico de Almeida***; Luciana \\ Oliveira Rangel Pinheiro****; Patrícia Suguri Cristino $* * * * *$
}

* Residente do programa de Residência Multiprofissional em Saúde da Família, Escola Nacional de Saúde Pública Sérgio Arouca/ FIOCRUZ

** Residente do programa de Residência Multiprofissional em Saúde da Família com ênfase na população do campo, Universidade de Pernambuco

*** Doutora, Professora Adjunta, Faculdade de Odontologia da Universidade Federal da Bahia

**** Doutora, Professora Adjunta, Escola Bahiana de Medicina e Saúde Pública

***** Doutoranda, Professora Adjunta, Faculdade de Odontologia, Universidade Federal da Bahia

Recebido: 30/06/2021. Aprovado: 19/10/2021.

\section{RESUMO}

Desde os anos 1990, iniciou-se uma luta pela implementação de programas de qualificação dos recursos humanos para o trabalho no Sistema Único de Saúde (SUS), a exemplo do Programa de Educação pelo Trabalho na Saúde (PET Saúde). Apesar dos avanços, ainda persistem lacunas importantes na integração ensino-serviço-comunidade. Nesse sentido, o objetivo nesta pesquisa é analisar a percepção de egressos do curso de Odontologia da Escola Bahiana de Medicina de Saúde Pública sobre a vivência no Estágio Supervisionado na Atenção Primária em Saúde (APS). Trata-se de um estudo exploratório, de abordagem qualitativa, com a utilização de 12 entrevistas semiestruturadas individuais, realizadas presencialmente e à distância, submetidas à análise de conteúdo de Bardin. As categorias de análise foram: 1. As concepções sobre o SUS e a APS; e 2. $\mathrm{O}$ aprendizado no estágio e a qualidade da preceptoria. A principal contribuição sentida pelos egressos foi o desenvolvimento humanístico. A qualificação dos preceptores foi percebida como necessária para o êxito do estágio. Os resultados deste estudo reforçam a relevância da integração ensino-serviço-comunidade.

Descritores: Sistema Único de Saúde. Atenção Primária à Saúde. Saúde Pública. Estágio. 


\section{INTRODUÇÃO}

Os cursos de graduação em saúde no Brasil têm como desafio superar as consequências flexnerianas do modelo de formação ainda hegemônico: tecnicista e biologicista, voltado para a cura de doenças e com foco no indivíduo. Tais características dificultam (ou até mesmo impedem) que os profissionais saibam trabalhar, na prática, com a promoção da saúde ${ }^{1}$.

Vale ressaltar que a consolidação do Sistema Único de Saúde (SUS) depende da construção e fortalecimento de processos de trabalho através de equipes multiprofissionais, capazes da produção do cuidado de forma interdisciplinar e interinstitucional. Ainda é marcante a falta de vivência nos cenários de prática durante os cursos de graduação em saúde ${ }^{2}$.

Diante disso, serviços de saúde e corporações acadêmicas necessitam de uma intersecção para reorganização do ensino (quando não, também, do próprio serviço) que contribua para a formação generalista, com visão humanística, crítica e reflexiva e com capacidade de articular os conhecimentos teóricos e práticos no entendimento biopsicossocial dos indivíduos e coletividades, como demarcam as Diretrizes Curriculares Nacionais (DCN) para os cursos de Odontologia. ${ }^{3}$

Propostas em 2002, as DCN significaram um marco inicial para a superação de antigos (e persistentes) paradigmas do ensino - como o currículo mínimo, centrado em conteúdos e na pedagogia tradicional verticalizada, de transmissão de conhecimentos - para o desenvolvimento de habilidades e competências gerais e específicas, para atuação em equipes capazes de responder às necessidades do sistema de saúde vigente no país ${ }^{3}$.

No entanto, somente as DCN não são suficientes para induzir as mudanças necessárias na academia e nos serviços de saúde. Assim, foram implantados alguns programas interministeriais -Ministérios da Saúde (MS) e da Educação (MEC) - como o Programa de Educação pelo Trabalho na Saúde (PET Saúde), em 2007, como financiamento de projetos de intervenção que envolvessem a parceria entre Instituições de Ensino Superior (IES) e do SUS, em todo o território nacional ${ }^{4}$.

Em 2016, a Escola Bahiana de Medicina e Saúde Pública (EBMSP), localizada em Salvador - BA, foi a única IES privada do estado baiano a ser contemplada pelo edital do PET-SAÚDE GraduaSUS, por meio de projeto em parceria com a Secretaria Municipal de Saúde (SMS) de Salvador/BA, vigente entre maio de 2016 e maio de 2018, com três grupos: Medicina, Odontologia e Enfermagem.

O grupo de Odontologia teve como uma das suas principais ações a implantação de um Curso de Preceptoria para dentistas da Atenção Primária em Saúde (APS), formalizado institucionalmente sob a forma de atividade de extensão. Contou com dentistas de Unidades Básicas de Saúde (UBS) e Unidades de Saúde da Família (USF) de três Distritos Sanitários de Salvador, que passaram a receber estudantes de odontologia da EBMSP em articulação com alguns componentes curriculares, entre eles o Estágio Supervisionado (Saúde Coletiva V nesta IES) ${ }^{5}$.

O curso introdutório de preceptoria foi concebido e conduzido dentro dos princípios da Educação Permanente em Saúde (EPS), com a participação ativa de dentistas durante todo o planejamento e execução, o que permitiu efetivar ajustes demandados pela prática da preceptoria durante 0 processo de formação ${ }^{6}$. Após a finalização do curso referido, os docentes de Estágio Supervisionado assumiram o compromisso de dar continuidade à EPS, ofertando, em todos os semestres, oficinas de atualização (com temas escolhidos pelas preceptoras e participação estratégica de docentes de outros componentes do curso)e rodas de 
conversa para acolhimento, monitoramento e avaliação das vivências de estudantes e preceptoras(es) na APS.

De acordo com a Associação Brasileira de Ensino Odontológico (ABENO), o Estágio Supervisionado (com atividades intra e ou extramuros, desenvolvidas em serviços públicos ou privados) é o instrumento de integração e conhecimento de estudantes com a realidade social, econômica e do trabalho, na direção da atenção integral, devendo incluir a educação e promoção da saúde ${ }^{7}$.

A vivência qualificada nos campos de estágio na APS favorece alguns discernimentos essenciais, tais como: o "serviço de saúde como recurso ou intruso; território como potência de vida", que nenhum componente teórico seria capaz de produzir.

Considerando esse contexto de formação e trabalho, o objetivo desse estudo foi conhecer as percepções de egressos do curso de Odontologia da EBMSP acerca da vivência de Estágio na APS realizada durante a formação de preceptores.

\section{MÉTODO}

Trata-se de um estudo exploratório, com abordagem qualitativa, utilizando-se de entrevista individual semiestruturada para a coleta de dados a partir de um roteiro inicial de perguntas.

Todas(os) as(os) egressas(os) do curso de odontologia da EBMSP formadas(os) em $2017.2 \mathrm{e}$ em 2018.1 que cumpriram a carga horária prática de Estágio em Saúde Coletiva V na APS foram convidadas(os) a participar do presente estudo uma amostra intencional ${ }^{9}$ na medida em que os sujeitos foram acessados entre os que detinham os atributos de interesse. $\mathrm{O}$ convite foi realizado por meio de correio eletrônico, com o Termo de Consentimento Livre e Esclarecido (TCLE). Apenas 12 egressas(os) manifestaram a vontade de participar do estudo, não se alcançando, nesses termos, o critério de saturação, o que não compromete a validade da investigação, como destaca, mais recentemente, Minayo ${ }^{10}$. Cabe frisar que uma das limitações da pesquisa foi o tempo para a coleta de dados (deriva-se de um Trabalho de Conclusão de Curso de Graduação).

Cinco entrevistas foram realizadas de forma presencial, em locais combinados entre as pesquisadoras e os sujeitos da pesquisa. Sete entrevistas precisaram ser feitas de modo remoto, com a utilização da ferramenta eletrônica Skype ou Facetime, com aqueles que não residiam em Salvador. Todas as entrevistas foram audiogravadas e posteriormente transcritas, com o consentimento das(os) participantes (via assinatura do TCLE).

Os dados (as falas transcritas) foram analisados pelo método de Análise de Conteúdo ${ }^{11}$. Em virtude do limite de páginas, apenas duas categorias de análise foram discutidas neste artigo: 1. As concepções sobre o SUS e APS; e 2. O aprendizado no estágio e a qualidade da preceptoria.

Atendendo às definições da Resolução 466/12 do Conselho Nacional de Saúde, o projeto deste estudo foi aprovado pelo Comitê de Ética em Pesquisa (CEP) da Fundação Bahiana de Desenvolvimento das Ciências (FBDC), sob protocolo de número 2.915.545, de 25 de setembro de 2018. O projeto que deu origem a este estudo foi maior, também conduzido pelas pesquisadoras em questão, do qual um dos objetivos foi extraído para os fins do presente artigo.

\section{RESULTADOS E DISCUSSÃO}

Foram 12 sujeitos participantes da pesquisa: 6 concluintes em 2017.2 e 6 concluintes em 2018.1. Do total, 10 do sexo feminino e 2 do sexo masculino. Em relação à inserção profissional, 06 estavam na Estratégia Saúde da Família (ESF) (por meio de contrato), 08 em consultório particular (por porcentagem e 
planos de saúde) e 2 destes conciliavam a ESF e o consultório particular. No que se refere à pósgraduação, 04 se encontravam em curso de especialização: 02 conciliavam com o trabalho em consultório particular, 1 com a ESF e 1 estava na Residência Multiprofissional do SUS.

A seguir, serão apresentados os resultados, considerando as categorias de análise mencionadas. Para a preservação da identidade, os sujeitos participantes receberam apelidos fictícios, com nomes de flores.

\section{A concepção sobre o SUS e a Atenção Primária em Saúde}

Entre os 12 sujeitos entrevistados, existiram diferentes concepções no tocante ao SUS:

"O preconceito com a saúde pública é muito grande aqui dentro da faculdade [...]eu achava que era uma coisa completamente diferente [...] que ia estar lá e não ia ter nada pra fazer, porque não ia ter material, porque não ia conseguir fazer uma restauração, porque não ia ter nada e vi que não é a realidade." [Cravo]

Apesar de possuirmos um dos maiores e mais complexos sistemas de saúde pública do mundo, foi notória a reprodução de falas do senso comum entre egressas(os), aparentemente ainda muito influenciadas(os) pela mídia e insuficientemente sensibilizadas(os) pelo ensino da Saúde Coletiva na graduação.

As principais imagens e informações sobre o SUS veiculadas pela mídia associam-no regularmente às ausências, mazelas e precariedades, enfatizando de maneira contumaz uma suposta ineficiência do Estado, incompetência das autoridades e/ou dos profissionais de saúde. Disso, resulta a formação de uma ordem simbólica pouco reflexiva sobre o campo da política de saúde que o SUS representa, desestimulando, inclusive, a participação cidadã (tão essencial para sua consolidação). A imagem de fracasso da saúde pública no Brasil perpassa diferentes níveis de escolaridade e classes sociais. A forma e o conteúdo (majoritariamente dramáticos) das notícias dão conta de um SUS generalizadamente "deficiente" e "não resolutivo", por todo o país ${ }^{12}$.

Sobre a "ordem simbólica", cabem algumas reflexões do campo jornalístico sobre a estreita relação da mídia com a saúde, ancoradas em alguns conceitos do sociólogo Pierre Bourdieu. O poder nas relações de comunicação depende (na forma e no conteúdo) do poder material ou simbólico acumulado pelos agentes sociais envolvidos nessas relações, e que a partir disso podem permitir acumular poder simbólico, ou seja, um poder de construção da realidade. Os sistemas simbólicos constituem-se como instrumentos de conhecimento e de comunicação aplicados para a determinação ou para o reconhecimento da dominação. Entretanto, esses sistemas desempenham a função de garantir a dominação de uma classe sobre a outra, o que se configura como uma violência simbólica, que se exerce de maneira subentendida ou inconsciente (tanto por dominantes quanto por dominados). Perante isso, faz-se necessário desmontar uma série de mecanismos que empoderam a mídia a exercer influência nos agentes sociais (pessoas e instituições) e negociar seu modo de perceber o mundo e a sua sociedade ${ }^{13}$.

E não seria papel da formação acadêmica fomentar a criticidade com relação a algumas distorções promovidas pela mídia? Para Bourdieu $(2009)^{14}$, a escola é um lugar de reprodução da sociedade, o que nos inspira a uma autocrítica profunda e vigilante. Para o otimismo necessário à luta, a obra de Paulo Freire (2017) ${ }^{15}$ nos convida para a ação transformadora e libertadora.

Outro aspecto que se destacou no estudo foi a visão do SUS vinculada à pobreza, isto é, a construção da lógica do SUS como um sistema para pobres. Paim (2009) ${ }^{16}$ sistematizou algumas 
concepções a respeito do sistema: o SUS para pobres, o SUS real, o SUS formal e o SUS democrático.

"Na Atenção Básica, como você atende muitas pessoas fora da sua realidade [...] é bom para quebrar aquela visão que muitos dentistas têm, inclusive muitos estudantes, porque o paciente é mais pobre posso fazer de qualquer jeito; não!" [Cravo]

Para além da concepção do "SUS para pobres", o trecho em destaque denuncia a desvalorização do ser, do humano:

"A lógica racional embrutece, tirando dos indivíduos a espontaneidade, incentivando-os à participação por meio de ideologias e formas coercitivas no jogo capitalista; submete-os a uma sociedade de excedentes que valoriza o capital antes da vida, valorizando a vida somente como produtora de capital"17.

"Pretendo sair do PSF, para ter melhor condição de trabalho, atender outro tipo de população, exercer uma odontologia como aprendi na faculdade." [Lírio]

O desejo de "atender outro tipo de população" pode ter a ver com a valorização da vida "como produtora de capital". Quanto à "odontologia que aprendi na faculdade", uma possível explicação pode estar no tecnicismo, comentado mais adiante.

Dentro do SUS, o lócus da APS é ainda mais desvalorizado:

"Tenho vontade de seguir no serviço público, mas o fato de ser limitado, isso às vezes me coloca um pouquinho para trás, porque eu acho que não posso crescer muito como profissional, a gente não tem muito o que fazer com o paciente [...] porque querendo ou não, você acaba se tornando um clínico geral." [Violeta]

$\mathrm{O}$ trabalho na APS requer o desenvolvimento de habilidades e competências que nenhuma especialidade isolada será capaz de fornecer (reconhecer e atuar sobre os determinantes sociais de saúde, tomar decisões baseadas em evidências científicas tanto no âmbito individual como no coletivo, saber identificar necessidades locais para planejar, monitorar e impactar positivamente a saúde das comunidades, saber se comunicar e interagir com outros profissionais de saúde e com a população em geral, ser capaz de atuar nos territórios de forma interprofissional, ínterinstitucional e transdisciplinar, entre outras ${ }^{17}$. Ou seja, é preciso "crescer muito como profissional" para desempenhar-se bem nesse lugar. Provavelmente, o crescimento profissional citado por Violeta se paute em outras questões, como o desejo de atuar somente dentro de alguma(s) especialidade(s) na lógica da esfera privada.

O SUS configura a maior política de inclusão social da história do Brasil, e as estratégias definidas para sua APS têm sido consideradas, por sua extensão e cobertura, um modelo a ser seguido por outros países ${ }^{18}$. No entanto, os limites do serviço ainda são reais:

"É material que falta, instrumento velho, quebrado, que não funciona da melhor maneira que poderia, que são de marcas ruins, que não exerce a função adequada." [Lírio]

"Apesar de [na unidade] não faltar [materiais], não quer dizer que estes são da melhor qualidade, então acontece da restauração cair, porque o adesivo não é bom e a prefeitura não quer comprar um melhor, da resina ser velha, de faltar agulha média e a gente só ter longa e tem que se virar com isso." [Cravo]

Não se pretende aqui aceitar as mazelas do serviço como condições com as quais se deve habituar. Muitas lacunas relatadas são, de fato, inaceitáveis para o trabalho em saúde, pois 
comprometem a biossegurança, a longevidade dos procedimentos e a própria saúde do usuário e do trabalhador. Contudo, é preciso fazer reflexões críticas sobre o uso das tecnologias, a produção do cuidado e as demais características desejáveis para o processo de trabalho, na vivência do estágio na APS.

\section{O aprendizado no estágio e a qualidade da preceptoria}

Um estudo semelhante com egressos mostrou que os estudantes apresentavam um medo inicial para atuar no ambiente da saúde pública; medo este vencido pela possibilidade de conhecer coisas novas e métodos pouco abordados no ambiente acadêmico ${ }^{19}$.

Apenas um dos 12 sujeitos deste estudo afirmou não ter obtido aproveitamento significativo com o estágio na ESF.

"Tive algumas dificuldades, por exemplo, fiquei indo para lá sem atendimento nenhum [...] tinham poucos kits clínicos, então tinha limitação de quantos pacientes atender por turno [...] não foi muito proveitoso, porque tive essas intercorrências, e também o dia que eu estava no estágio, um turno era reunião da preceptora, então ficava lá sem fazer nada." [Orquídea]

O fazer na APS está para muito além do atendimento no consultório e, ainda que seja de grande importância, é pertinente refletir sobre os "porquês" das "limitações e intercorrências", o significado das reuniões de equipe e as tantas outras atribuições de uma Equipe de Saúde Bucal na ESF, dentro e fora das unidades de saúde ${ }^{8}$. Essa fala mostrou o quanto precisamos apoiar a preceptoria, no sentido de utilizar todas as situações como oportunidades de aprender e ensinar, não apenas sobre o serviço, mas sobre os próprios desafios e, especialmente, os modos de defender o SUS.
Os demais sujeitos trouxeram relevantes relatos acerca do processo de aprendizagem no ambiente da APS:

"A relação com o paciente é ainda melhor, porque na verdade você não se vê naquela cobrança de se ver uma 'vendedora','[...]. [Icsória]

Em algum momento da trajetória do egresso a saúde se consolida como algo a ser "comercializado". Contrariamente, essa fala revela certo conforto em se poder trabalhar sem essa "cobrança". Talvez a vivência do cuidado em outras dimensões possa fortalecer modos diversos de ver o trabalho em saúde: "cuidar da inteireza do ser humano [...]. Facilitar, enfim, que o mistério da vida possa nos cuidar, já que é cuidando que seremos cuidados" 20 .

"Até protocolo de restauração de amálgama, que nunca tinha feito na faculdade, a gente fez bastante, então querendo ou não, você acaba tendo um contato maior com coisas que você não vê na faculdade." [Icsória]

Essa fala denuncia a já conhecida distância entre o ensino da graduação e o cotidiano da APS. Uma das ações do grupo de odontologia do PETSAÚDE GraduaSUS foi promover rodas de conversa entre o corpo docente e as preceptoras do PET, incluindo a Coordenadora de Saúde Bucal do município. A dificuldade de estagiárias(os) para fazer essas restaurações (com amálgama) foi trazida pelas preceptoras e acolhida pelo corpo docente, que, a partir de então, começou a incentivar a realização desses procedimentos na clínica-escola. O descompasso em questão se dá em função do apelo estético do mercado e da sociedade que acaba adentrando na odontologia de um modo geral. Trata-se da supremacia estética descontextualizada da realidade epidemiológica da saúde bucal local e brasileira.

É preciso que exista uma relação dialógica entre o ensino intramuros e o estágio, uma vez 
que este funciona como importante sinalizador do mundo do trabalho, como descrito na própria Lei do Estágio (2008) ${ }^{21}$ :

Art. $1^{\circ}$ Estágio é o ato educativo escolar supervisionado, desenvolvido no ambiente do trabalho, que visa à preparação para o trabalho produtivo de educandos. [...] $O$ estágio visa ao aprendizado de competências próprias $d a$ atividade profissional $e$ à contextualização curricular, objetivando o desenvolvimento do educando para a vida cidadã e do trabalho.

"Eu pude ver até minha comunidade com outros olhos, como profissional de saúde. Foi muito enriquecedor para mim [...] outra questão que aprendi foi a "me virar", [...]hoje eu to numa realidade pior, porque eu to na zona rural [...] então eu aprendi a virar no estágio, $e$ isso me ajudou um pouco com a experiência que to tendo hoje dentro do $P S F$." [Margarida]

Margarida teve a oportunidade de fazer o estágio em uma USF do bairro onde morava, em Salvador. Daí esse relato, de poder ver sua comunidade "com outros olhos". Havia satisfação ao dizer isso durante a entrevista. O "se virar", refere-se ao (des)encontro com a realidade, que impõe dificuldades evitadas na clínica-escola. $\mathrm{O}$ ambiente intramuros, sob o argumento da excelência científica, desconecta-se da realidade para proporcionar as condições "ideais": os melhores materiais e equipamentos, um turno inteiro para atender um único paciente etc. $\mathrm{O}$ campo de estágio nas unidades de saúde do SUS aproximam os estudantes da realidade das comunidades $^{22,23}$.

"Às vezes a gente ia atender uma pessoa, aí chegava a mãe, a esposa e o filho para a gente atender, o que não é nossa realidade na graduação, e às vezes a gente ia fazer visita nas casas, então a gente conhecia o paciente além das quatro paredes do seu consultório, então eu achei isso muito legal. [...] é onde você se sente mais útil como dentista, como pessoa, e é onde você sai mais humanizado, porque é muito difícil você passar por uma experiência dessas e não sair mais humanizado." [Margarida]

As visitas domiciliares, frequentemente, aproximam diferentes profissionais que atuam na APS. Um relato de experiência sobre a atuação multiprofissional em estágio extramuros ${ }^{23}$ mostrou que, apesar de todo o preparo durante a graduação, essa articulação possibilitou a produção de novos conhecimentos e a aquisição de condutas interprofissionais na produção do cuidado, permitindo espaço para que todos os sujeitos envolvidos exercessem seus papéis sociais e realizassem um fluxo e um influxo de saberes e modos de fazer. Nesse contexto, a produção do cuidado acontece de maneira mais integral, contribuindo para que conceitos humanísticos sejam vivenciados e partilhados na prática.

Sobre "o manejo do lado humano que a gente não vê na graduação", a preceptoria na APS tem por compromisso a articulação do Trabalho Morto (caracterizado pelas tecnologias duras, a exemplo de produtos e equipamentos) com o Trabalho Vivo (relacional, aplicado a situações reais do cotidiano da vida social), e, nessa articulação, possibilitar o ambiente de ensino e a produção de conhecimento ${ }^{24}$.

O trabalho interprofissional promove a troca de saberes entre preceptores, estudantes e usuários. É uma via de mão dupla, na medida em que a presença do estudante no serviço pode estimular seu crescimento e incentivar o desejo de aprender. Da mesma forma, pode animar preceptores na busca de novos conhecimentos e estimular o pensamento reflexivo, ao participarem diretamente na formação de novos 
profissionais $^{25}$.

A preceptoria também pode colaborar com relação ao manejo de registros e documentos, essenciais na rotina do serviço:

"Minha preceptora conseguiu organizar tudo que ela queria me passar e conseguiu, até a parte burocrática, de assinar papeis, de assinar os números, eu participei também de reuniões multidisciplinares, que envolviam vários profissionais, sobre nutrição, fumantes.[...]Eu sempre paro para conversar com meus pacientes, sobre prevenção [...] que eu aprendi lá." [Violeta]

Mas, nem sempre é assim:

"Minha dificuldade foi mais com minha preceptora, não como pessoa, como pessoa ela é ótima, mas eu achei que faltou um pouco de preparo da parte dela como preceptora. [...] que faltou um pouco mais de organização da parte dela, planejar um pouco os dias que eu estava lá." [Rosa]

Apesar de a entrevista ter foco na APS, houve um relato sobre o estágio em ambiente hospitalar dentro do mesmo componente de Estágio Supervisionado:

"Foi uma experiência boa, mas não me acrescentou muito na minha vida profissional, até porque tinha preceptores que fazia rapidinho, atendia 2, 3 pessoas e pronto, ia embora." [Violeta]

Nesse sentido, esforços vêm sendo realizados pela EBMSP com o intuito de auxiliar na formação permanente de preceptores:

"A gente foi beneficiado com um curso de formação de preceptores para nossos preceptores nas sextas-feiras à tarde. Pelo que a gente percebeu, eles tinham um manejo daquilo que estava lá. Quem aceitou ser preceptor tinha um gosto pelo serviço dentro da carreira do SUS, e eles tinham uma articulação... uma visão interessante. [...] [O preceptor] conseguia me mostrar a teoria com a prática muito grande. Então a gente passou por práticas de acolhimento, coisas que a gente tinha visto muito na teoria, e na prática a gente sabe que não é todo lugar que tem." [Gardênia]

\section{CONCLUSÕES}

Apesar das lutas para mudança do perfil profissional, ainda existe um distanciamento entre o que se ensina no âmbito acadêmico e o que se espera dos profissionais que trabalham no SUS.

Os resultados deste estudo reforçam a relevância da integração ensino-serviçocomunidade para o estreitamento entre a teoria e a prática da Saúde Coletiva, já que a integração citada possibilita a apropriação e intervenção sobre a realidade social e sanitária de comunidades e a vivência de maneira refletida e crítica nos cenários reais da APS.

O desenvolvimento humanístico e a (re)significação a respeito do processo saúdedoença foram as contribuições mais relatadas entre as(os) egressas(os) do estágio na APS, com impactos na vida pessoal e profissional das(os) entrevistadas(os).

Houve um reconhecimento sobre a importância da qualificação da preceptoria para o êxito da experiência de estágio na APS, em busca da integração ensino-serviçocomunidade.

\section{AGRADECIMENTOS:}

As autoras manifestam seus agradecimentos à Escola Bahiana de Medicina e Saúde Pública, por todo o apoio e confiança no trabalho desenvolvido, assim como ao Ministério 
da Saúde do Brasil, pela iniciativa do PET GraduaSUS, um programa fundamental para experiências formativas verdadeiramente transformadoras, como as relatadas neste trabalho.

\section{ABSTRACT \\ Perceptions of graduates of the dentistry course about supervised internship in Primary Health Care}

Since the 1990s, one has started an effort to implement programs to qualify human resources for work in the SUS (Sistema Único de Saúde - Brazilian Unified Health System), such as the Education Program for Work in Health (PET-Saúde). Despite advances, there are still important gaps in the teaching-servicecommunity integration. The objective of this research was to analyze the perception of graduates of the Dentistry course at the Bahian School of Public Health and Medicine about the experience of Supervised Internship in Primary Health Care (PHC). This is an exploratory study, with a qualitative approach, using 12 semi-structured interviews, performed in person and remotely, submitted to Bardin's (2011) content analysis. The categories of analysis were: 1. Conceptions about the SUS and PHC; 2 . Learning in the internship and the quality of tutoring. The main contribution felt by the graduates was the humanistic development. The qualification of the preceptors was perceived as necessary for the internship's success. The results of this study reinforce the importance of teaching-servicecommunity integration.

Descriptors: Unified Health System. Primary Health Care. Public Health. Internship.

\section{REFERENCIAS}

1. Emmi DT, Silva DMC, Barroso RFF. Experiência do ensino integrado ao serviço para formação em saúde: percepção de alunos e egressos de Odontologia. Interface Comun Saúde Educ.2018; 22(64):223-36.

2. Silva CA, Araújo MD. Programa de
Residência Multiprofissional em Saúde: o que mostram as publicações. Saúde Debate. 2019; 43(123):1240-58.

3. Brasil. Conselho Nacional de Educação. Câmara de Educação Superior. Resolução CNE/CES 3/2002, de 2002. Institui Diretrizes Curriculares Nacionais do Curso de Graduação em Odontologia. Diário Oficial da União, Brasília (4 de março de 2002). Seção 1, p. 10.

4. Morita MC, Kriger L, Carvalho ACP, Haddad AE. Implementação das Diretrizes Curriculares Nacionais em Odontologia. $1^{\mathrm{a}}$ ed. Maringá: Dental Press Editora; 2007.

5. Cristino PS, Silva MMC, Almeida TF, Antunes HS, Mendonça TT. Relato PETSaúde/GraduaSUS: trajetória da Odontologia em uma instituição privada, 2016-2017. Rev ABENO. 2018;18(4):160-8.

6. Cristino PS, Silva MMC, Almeida TF, Corrêa AP, Mendonça TT, Antunes HS, Sampaio CRP. Integração ensino-serviçocomunidade a partir da articulação ensino, pesquisa e extensão: um relato de experiência do grupo de odontologia do PET Saúde GraduaSUS da Escola Bahiana de Medicina e Saúde Pública (EBMSP) e Secretaria Municipal de Saúde (SMS) de Salvador, BA. In: Carrer FCA. SUS e Saúde Bucal no Brasil: relação ensino-serviço. São Paulo: Faculdade de Odontologia da USP; 2019. p.112-116. [Acesso em 12 nov. 2021]. Disponível em: http://www.fo.usp.br/wpcontent/uploads/2019/04/Rela\%C3\%A7\%C3 \%A3o-Ensino-Servi\%C3\%A7o-1.pdf.

7. Associação Brasileira de Ensino Odontológico. Diretrizes da ABENO para a definição do estágio supervisionado nos cursos de Odontologia. Rev ABENO. 2002; 2(1):39.

8. Cardoso FM, Campos GW. Aprendendo a clínica do sofrimento social: narrativas do 
internato na Atenção Primária à Saúde. Ciênc Saúde Colet. 2020; 25(4): 1251-60.

9. Minayo MCS. O desafio do conhecimento: pesquisa qualitativa em saúde. $11^{\mathrm{a}}$ ed. São Paulo: HUCITEC; 2008.

10. Minayo MCS. Amostragem e saturação em pesquisa qualitativa: consensos e controvérsias. RPQ. 2017; 5(7):1-12.

11. Bardin L. Análise de conteúdo. $4^{\mathrm{a}}$ ed. São Paulo: 70a ed.; 2011. p. 225-400.

12. Moraes JCO, Carneiro CR, Vale da Cruz HRF, Costa IP, Almeida MR. A Mídia e sua Relação com a Formação de Opiniões Sobre o Sistema Único de Saúde. Rev Bras Ciênc Saúde .2017; 21(2): 103-10.

13. Langbecker A. Campo Jornalístico: Reflexões para Saúde Coletiva. Lima: Asociación LatinoAmericana de Investigadores de la Comunicación; 2014. [Acesso em 12 nov. 2021]. Disponível em: http://congreso.pucp.edu.pe/alaic2014/wpcontent/uploads/2013/09/Andrea-Langbec ker.pdf.

14. Bourdieu P, Passerom JC. A reprodução: elementos para uma teoria do sistema de

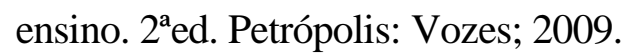

15. Freire P. Pedagogia do oprimido. $64^{\mathrm{a}}$ ed. Rio de Janeiro/São Paulo: Paz e Terra; 2017.

16. Paim JS. O que é o SUS. $1^{\text {a }}$ ed. Rio de Janeiro: Editora Fiocruz; 2009.

17. Araujo SM, Cianalli DL. Trabalho e sobrevivência - o mundo da vida sob ameaça: racionalidade ou irracionalidade? Soc estado, Brasília, 2016; 21(2): 289-312.

18. Mendes EV. 25 anos do Sistema Único de Saúde: resultados e desafios. Estudav. 2013; 27(78):27-34.

19. Bulgarelli AF, Souza KR, Baumgarten A, de Souza JM, Rosing CK, Toassi RFC. Formação em saúde com vivência no Sistema Único de Saúde (SUS): percepções de estudantes do curso de Odontologia da
Universidade Federal do Rio Grande do Sul. Interface Comun Saúde Educ. 2013; 18(49): 351-62.

20. Leloup JY, Crema R. Dimensões do cuidar: uma visão integral. In: Introdução do livro. Petrópolis: Vozes; 2015. p. 17.

21. Brasil. Lei $n^{\circ} 11.788$, de 25 de setembro de 2008. Dispõe sobre o estágio de estudantes. [Acesso em 12 nov. 2021]. Disponível em: http://www.planalto.gov.br/ccivil_03/_ato200 7-2010/2008/lei/111788.htm.

22. Madruga LMS, Ribeiro KSQS, Freitas CHSM, Perez IAB, Pessoa TRRF, de Brito GEG. O PET-Saúde da Família e a formação de profissionais da saúde: a percepção de estudantes. Interface comun saúde educ.2015; 19(1): 805-16.

23. Silva Junior MF, Pacheco KTS, de Carvalho RB. Multiplicidade de atuações do acadêmico de Odontologia no estágio curricular: relato de experiência. Arq Odontol. 2015; 51(4): 194-204.

24. Merhy EE, Franco TB. Trabalho em saúde. In: Pereira IB, Lima JCF, organizadores. Dicionário da Educação Profissional em Saúde [internet]. Rio de Janeiro: Fiocruz; 2009. [Acesso em 12 nov. 2021]. Disponível em: http://www.sites.epsjv.fiocruz.br/\%20di cionario/verbetes/trasau.html.

25. Lima PAB, Rozendo CA. Desafios e possibilidades no exercício da preceptoria do Pró-PET-Saúde. Interface Comun Saúde Educ.2015; 19(1): 779-91.

\section{Correspondência para:}

Tatiana Frederico de Almeida e-mail: tatifrederico@yahoo.com.br Universidade Federal da Bahia Rua Araújo Pinho, 62, 6º andar - Canela 41110-150 Salvador/BA 